\title{
Prostate Adenosquamous Carcinoma
}

National Cancer Institute

\section{Source}

National Cancer Institute. Prostate Adenosquamous Carcinoma. NCI Thesaurus. Code C5538.

An infrequent invasive carcinoma of the prostate gland characterized by the presence of both glandular and squamous neoplastic components. It is more often located in the transitional zone of the prostate gland and it tends to rapidly metastasize to the bones. 